\title{
The beneficial role of rubble mound coastal structures on seawater oxygenation
}

\author{
E. I. Daniil, V. K. Tsoukala, C. I. Moutzouris \\ Laboratory of Harbour Works, Department of Civil Engineering, National Technical University of Athens, \\ 5 Iroon Polytechniou, 15773 Zografou, Greece
}

Received: 17 November 1999 / Revised: 7 April 2000 / Accepted: 16 May 2000

\begin{abstract}
The beneficial role of rubble mound coastal structures on oxygenation under the effect of waves is discussed, based on analytical considerations and experimental data from laboratory experiments with permeable and impermeable structures. Significant oxygenation of the wave-protected area was observed as a result of horizontal transport through the permeable structure. A two-cell model describing the transport of dissolved oxygen (DO) near a rubble mound breakwater structure was developed and used for the determination of the oxygen transfer coefficients from the experimental data. Oxygen transfer through the airwater interface is considered a source term in the transport equation and the oxygen flux through the structure is taken into account. The mass transport equations for both sides of the structure are solved analytically in terms of time evolution of DO concentration. The behaviour of the solution is illustrated for three different characteristic cases of initial conditions. The oxygen transfer through the air-water interface in the wave-influenced area increases the DO content in the area; the resulting oxygen flux through the structure is discussed. The analytical results depend on the initial conditions, the oxygen transfer coefficient and the exchange flow rate through the structure. Experiments with impermeable structures show that air water oxygen transfer in the harbour area is negligible in the absence of waves. In addition the ratio of the horizontal DO flux to the vertical flux into the seaward side tends towards a constant value, independent of the initial conditions.
\end{abstract}

Key words: Oceanography: physical (air-sea interactions; surface waves and tides)

\section{Introduction}

The role of coastal structures in seawater oxygenation has only recently been considered (Hosoi et al., 1990, 1995; Moutzouris and Daniil, 1995). Wave-breaking in the vicinity of coastal structures and beaches results in higher oxygenation rates associated with an improvement of water quality in the surrounding area (Moutzouris and Daniil, 1994; Tsoukala and Moutzouris, 1995). Breaking waves present a more difficult challenge compared to non-breaking waves, because of the gas transfer resulting from the entrapment of bubbles in the water body (Daniil and Moutzouris, 1993; Chanson and Cummings, 1993, 1994; Chanson and Lee, 1997; Asher et al., 1996; Asher and Wanninkhof, 1998). Plunging breaking waves generate turbulence and vorticity, which are of great importance for the solute and sediment transport in the surf zone (Lin and Liu, 1998). Data on oxygen transfer rates in the vicinity of an impermeable sloping beach and a rubble mound permeable breakwater as well as a vorticity-based model for gas transfer under breaking waves were presented by Daniil and Moutzouris (1995).

In the present work, experimental and analytical investigations of the beneficial role of rubble mound coastal structures on seawater oxygenation are presented. Experimental results show that significant harbour side oxygenation is the result of horizontal oxygen flux through the body of the structure, originating from oxygenation in the wave-influenced area. The oxygen transfer coefficients were determined from experimental data using a two-cell model. The structure is considered to be a barrier between the two cells and surface aeration is the main source of dissolved oxygen. The mass transport equations are solved analytically.

\section{Literature review}

Gas transfer is considered to be a first order process and is traditionally included as a source or sink term in the mass transport equation from which it may be deduced, 
once the remaining terms are known or accurately estimated. For low solubility and relatively unreactive compounds, the transfer is controlled by the water phase (Liss, 1983). The flux through the air-water interface is expressed as:

$J_{V}=K_{L}\left(\frac{C_{a}}{H^{\prime}}-C_{w}\right)$

where $J_{V}$ is the flux in units of mass per unit projected air-water surface area per unit time, $K_{L}(\mathrm{~m} / \mathrm{s})$ is the liquid film transfer coefficient or transfer velocity and characterizes the gas transfer process, $C_{a}$ is the gas concentration in the air, $H^{\prime}$ is the dimensionless Henry's law constant, $C_{w}$ is the gas concentration in the water and $C_{a} / H^{\prime}=C_{S}$ is the saturation concentration. A surface renewal model is often used for correlating the gas transfer coefficient with the flow characteristics. The first surface renewal model (Danckwerts, 1951; Bennett and Rathbun, 1972) expressed the transfer coefficient as a function of the rate of surface renewal:

$K_{L} \propto \sqrt{D_{m} \cdot r}$ or $K_{L} \cdot S c^{1 / 2} \propto \sqrt{v \cdot r}$

where $K_{L}$ is the transfer coefficient, $D_{m}\left(\mathrm{~m}^{2} / \mathrm{s}\right)$ is the molecular diffusivity of the gas in the water, $v\left(\mathrm{~m}^{2} / \mathrm{s}\right)$ is the kinematic viscosity of the water, $S c=v / D_{m}$ is the Schmidt number and $r\left(\mathrm{~s}^{-1}\right)$ is the average surface renewal rate.

For gas transfer under breaking waves Daniil and Moutzouris (1995) presented a vorticity-based renewal model, with the surface renewal rate expressed as:

$r=a_{r} \cdot \omega \cdot G r$

where $a_{r}$ is a constant of proportionality, $\omega=-\left(4 \pi f(\pi H / L)^{2}\right) /\left(1-(\pi H / L)^{2}\right)\left(\mathrm{s}^{-1}\right)$ is the wave vorticity at the water surface, $f\left(s^{-1}\right)$ the wave frequency, $H$ (m) the wave height, $L(\mathrm{~m})$ the wave length and $G r=(L / d)^{2}$ is a factor that expresses the influence of relative depth, where $d(\mathrm{~m})$ is the water depth.

The data from Daniil and Moutzouris (1995) were best fitted by:

$K_{L} S c^{1 / 2}=A(L / d)(v \omega)^{1 / 2}-B$

for an impermeable, smooth uniformly sloping beach with $A=2.86$ and $B=2.46 \times 10^{-3} \mathrm{~m} / \mathrm{s}$, and

$K_{L} S c^{1 / 2}=A^{\prime}(L / d)(v \omega)^{1 / 2}-B^{\prime}$

for a porous breakwater structure with $A^{\prime}=2.64$ and $B^{\prime}=2.93 \times 10^{-3} \mathrm{~m} / \mathrm{s}$.

The correlation coefficients for Eqs. (4) and (5) were high $\left(r_{c}>0.95\right)$. Although $A, B$ and $A^{\prime}, B^{\prime}$ do not differ significantly, the breakwater data appeared lower than the sloping beach data, for the range of wave characteristics considered.

Hosoi et al. (1990) and Hosoi and Murakami (1986) presented predictive equations for reaeration in the case of spilling and plunging breakers on a sloping beach. The transfer coefficients were found to be dependent on beach slope, offshore wave length and wave height, and water depth at the breaking point. Hosoi and Murakami
(1995) presented a reaeration model for permeable breakwaters consisting of a series of solid blocks with spaces between the individual blocks. The area behind the breakwater structure was not taken into account.

When neighbouring areas experience substantially different gas transfer, a horizontal flux develops, and should be taken into account. Horsch (1998), solving the problem of steady, diffusive-reactive transport in shallow triangular domain, concludes that vertical diffusion on a sloping bottom induces horizontal fluxes that can be important in specific physical situations.

For the analysis of data from laboratory flumes the unsteady one dimensional transport equation is used:

$\frac{\partial C}{\partial t}+\frac{\partial(U C)}{\partial x}=\frac{\partial}{\partial x}\left(D_{x} \frac{\partial C}{\partial x}\right)+S$

where $C$ is the concentration of dissolved oxygen, $U$ is the mean stream velocity in the $x$-direction $(U=0$ for the wave flume), $D_{x}$ is the longitudinal dispersion coefficient in the $x$-direction, $S$ is the source $(S>0)$ or sink $(S<0)$ term per unit volume, $\partial(U C) / \partial x$ is the horizontal advective transport and $\partial / \partial x\left(D_{x}(\partial C / \partial x)\right)$ is the term describing the horizontal dispersion and diffusion of dissolved oxygen. The oxygen transfer through the air water interface and can be expressed as a source term as:

$S=J_{V} A_{S} / V=K_{L}\left(C_{S}-C\right) A_{S} / V$

where $K_{L}$ is the oxygen transfer coefficient, $t$ is time, $A_{S}$ is the average air-water surface area on the horizontal plane and $V$ is the aerated water volume extending from the free surface to the bottom of the channel.

If the only source term is the air-water gas transfer, and horizontal transport and dispersion terms can be neglected, the transport equation is reduced to a first order differential equation. For the initial condition $C=C_{0}$ at $t=0$, the solution is:

$C_{i}=C_{S}-\left(C_{S}-C_{0}\right) \mathrm{e}^{-K_{L i}\left(A_{S i} / V_{i}\right) t}$

This solution is exact for the case of a completely mixed fluid volume. Equation (8) can be expressed as a linear function of time by taking algorithms. This expression is usually used for the determination of $K_{L}$.

\section{The two-cell model}

In the presence of porous rubble mound structure, horizontal transport terms cannot be neglected; two distinct areas should be considered: area (1) behind the structure, that represents the shoreward or harbour side, and area (2) in front of the structure, that represents the seaward side (see Fig. 1).

Equation (6) is discretized using a control volume approach (Patankar, 1980). Integrating over a control volume of length $L_{i}$, volume $V_{i}$, cross-sectional area equal to $W$ (width of the channel) times $d$ (the water depth), assuming that $\partial C / \partial t$ and $S$ can be represented by their values at point $i$ and a linear profile between grid points for $\partial C / \partial x$, Eq. (6) can be written: 


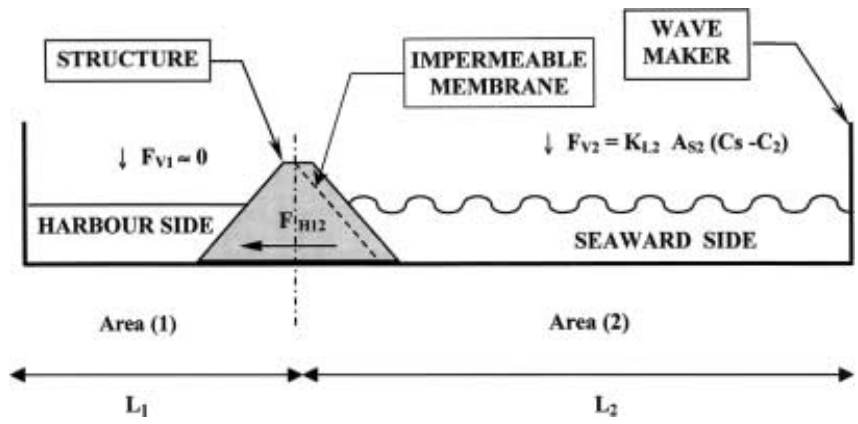

Fig. 1. Schematic layout of the laboratory wave flume

$$
\begin{aligned}
V_{i} \frac{\partial C}{\partial t}= & \frac{D_{i, i+1}}{L_{i, i+1}} W d\left(C_{i+1}-C_{i}\right) \\
& -\frac{D_{i-1, i}}{L_{i-1, i}} W d\left(C_{i}-C_{i-1}\right)+V_{i} S_{i}
\end{aligned}
$$

where $L_{i, i+1}, L_{i-1, i}$ is the distance and $D_{i, i+1}, D_{i-1, i}$ the horizontal diffusion coefficient between grid points $i$, $i+1$ and $i-1, i$ respectively.

Under the assumptions that the structure can be considered a barrier between the two sides, of negligible volume compared to the water volume in the flume, each side is well mixed, there is no significant inflow or outflow, and reaeration is the only source term, Eq. (9) can be written for the two areas as:

Area (1): $\quad V_{1} \frac{\mathrm{d} C_{1}}{\mathrm{~d} t}=\frac{D_{12} W d}{L_{12}}\left(C_{2}-C_{1}\right)$

Area (2): $\quad V_{2} \frac{\mathrm{d} C_{2}}{\mathrm{~d} t}=-\frac{D_{12} W d}{L_{12}}\left(C_{2}-C_{1}\right)$

$$
+K_{L 2} A_{S 2}\left(C_{S}-C_{2}\right)
$$

The subscripts 1, 2 denote values of the parameters in areas (1) and (2) respectively. The complete analytical solution of Eqs. (10) and (11) is given in Appendix I as:

$C_{1}=C_{S}-A_{1} \mathrm{e}^{-\gamma t}-B_{1} \mathrm{e}^{-\delta t}$

$C_{2}=C_{S}-A_{2} \mathrm{e}^{-\gamma t}-B_{2} \mathrm{e}^{-\delta t}$

where $A_{1}, A_{2}, B_{1}, B_{2}, \gamma, \delta$ are constants expressed as functions of the oxygen transfer coefficients, the diffusion coefficient, the geometric characteristics and the initial conditions. As shown in Appendix I, $\gamma-\delta>R>0$, therefore $1 / \delta>1 / \gamma$ and a time scale for the phenomenon is given by the quantity

$T=1 / \delta$.

The model described by Eqs. (10) and (11) is essentially a discretized form of the dispersion equation. The parameter

$Q_{12}=\frac{D_{12} W d}{L_{12}}$

is a lumped parameter incorporating the spatial variability of the diffusion coefficient. $Q_{12}$ is mathematically equivalent to the convective flow rate described by Stefan et al. (1989) and can be seen as an exchange flow rate between the two sides of the structure. $Q_{12}$ is expected to depend on the volume, porosity and permeability of the structure, as well as on wave dynamics.

The terms involved in Eqs. (10) and (11) are: the $D O$ change term, $V_{i} \mathrm{~d} C_{i} / \mathrm{d} t$ term of area $(i)$; the horizontal transport term, $F_{H 12}$, being the first right hand side term of Eqs. (10) and (11) and representing the transport through the body of the structure:

$F_{H 12}=\frac{D_{12} W d}{L_{12}}\left(C_{2}-C_{1}\right)=Q_{12}\left(C_{2}-C_{1}\right)$

and the reaeration or the oxygen transfer through the air-water interface, $F_{V i}$ being the vertical flux represented by the second right hand side term of the equations:

$F_{V i}=K_{L i} A_{S i}\left(C_{S}-C_{i}\right)$

The oxygen transfer terms are predominantly source terms.

If other fluxes need to be taken into account the model can be expanded to a mixed-cell in series model. Although a closed form analytical solution is no longer possible in this case, a unique solution can still be obtained (Stefan et al., 1989).

A numerical example of the behaviour of the solution is given in Fig. 2 for three different cases of initial DO concentration with negligible reaeration in area (1). DO -time histories for the harbour (area 1) and the seaward side (area 2), and the corresponding time evolution of fluxes for the seaward side are presented in dimensionless form. Parameter values representative of the performed experiments were assumed: $V_{1}=2.5 \mathrm{~m}^{3}$, $V_{2}=5 \mathrm{~m}^{3}, \quad d=0.7 \mathrm{~m}, \quad C_{S}=10 \mathrm{mg} / 1, \quad K_{L 1}=0, \quad K_{L 2}=$ $1.05 \times 10^{-4} \mathrm{~m} / \mathrm{s}$ and $Q_{12}=1.8 \times 10^{-3} \mathrm{~m}^{3} / \mathrm{s}$. DO concentration values are normalized with the saturation concentration $C_{S}$, time with $T$ and fluxes with the maximum possible reaeration flux, i.e. $K_{L 2} A_{S 2} C_{S}$.

Case (1) $C_{10}=0, \quad C_{20}=0 \mathrm{mg} / \mathrm{l}$. DO concentration evolution is similar in both areas and the vertical flux (reaeration) results mostly in an increase of the seaward DO concentration.

Case (2) $C_{10}=0, C_{20}=5 \mathrm{mg} / \mathrm{l}$. DO concentration of the seaward side exhibits an initial decrease and then resumes the typical behaviour increasing towards saturation. The initial increase of the seaward side DO concentration is considerably lower than that caused by reaeration.

Case (3) $C_{10}=5, C_{20}=0 \mathrm{mg} / \mathrm{l}$. DO concentration on the harbour side exhibits an initial decrease and then resumes the typical behaviour increasing towards saturation. The increase of the seaward DO concentration is initially higher than that due to reaeration alone.

\section{Limits of the flux ratios}

Part of the vertical flux $F_{V 2}$ goes into increasing the DO of the seaward side, while part will eventually contribute to increase DO of the harbour side, the latter through horizontal transport.

The ratio of the horizontal flux $\left(F_{H 12}\right)$ to the vertical flux $\left(F_{V 2}\right)$ is: 
Case 1

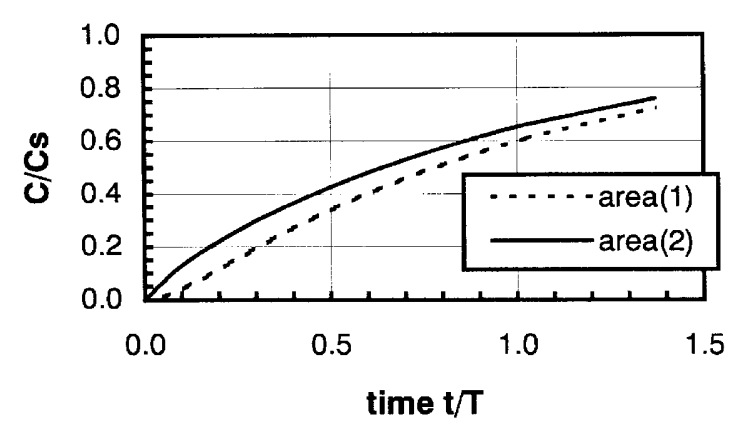

Case 2

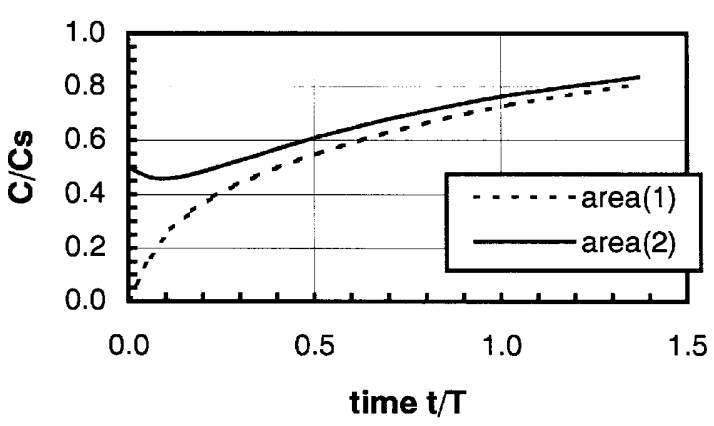

Case 3

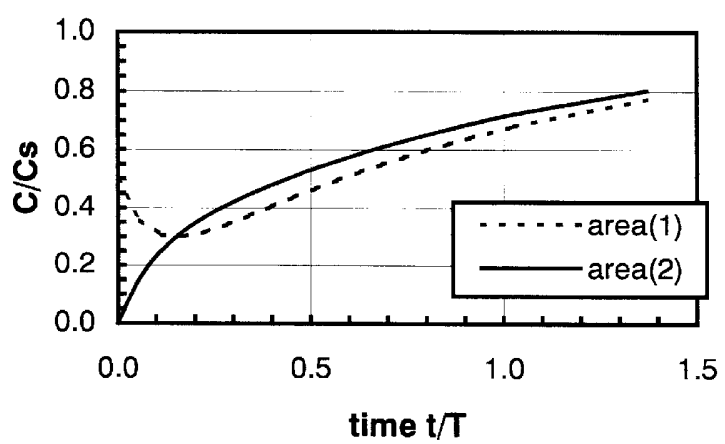

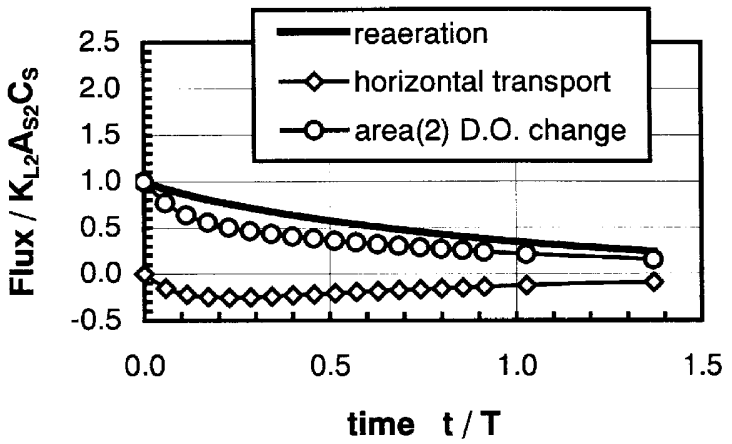
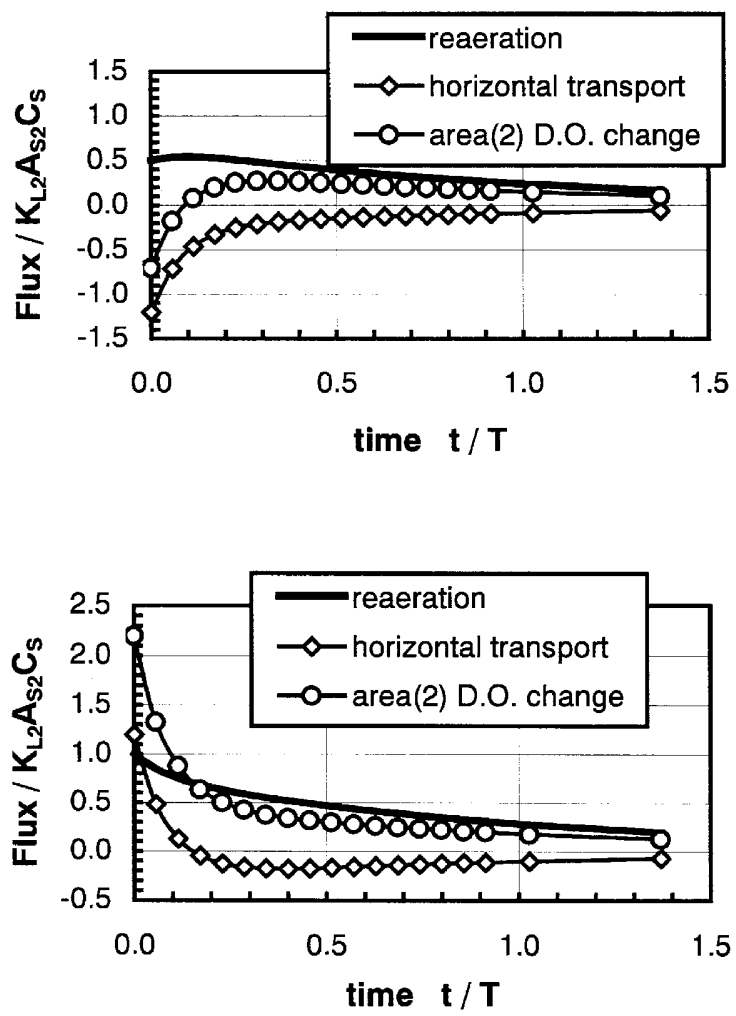

Fig. 2. DO time histories and time evolution of fluxes for cases (1), (2) and (3)

$\ell=\frac{F_{H 12}}{F_{V 2}}=\frac{Q_{12}}{K_{L 2} A_{S 2}}\left(\frac{C_{S}-C_{1}}{C_{S}-C_{2}}-1\right)$

\section{Initial flux ratio}

The initial flux ratio, for $t=0$ depends on the relative magnitude of the initial DO concentrations $C_{10}, C_{20}$ for areas (1) and (2) respectively. For $C_{10}=C_{20}$, there is no initial horizontal flux. Thus, the total incoming surface flux is translated into increase of the DO concentration of the seaward side. For $C_{10}<C_{20}$, the more commonly encountered situation in practice, the flux ratio is positive $(\ell>0)$, and the horizontal flux is towards the harbour $\left(F_{H 12}>0\right)$. For $C_{10}>C_{20}$, the horizontal flux is towards the sea. As a result, the initially observed DO change of the seaward side is higher, compared to the change caused by reaeration alone.

\section{Limiting flux ratio}

For $t=\infty$ Eq. (18) is written (see Appendix I):

$\ell(\infty)=\lim _{t \rightarrow \infty} \frac{F_{H 12}}{F_{V 2}}=\frac{Q_{12}}{K_{L 2} A_{S 2}}\left(\frac{B_{1}}{B_{2}}-1\right)$

As shown in Appendix I, the limiting flux ratio is independent of the initial conditions, and for $K_{L 1}=0$ depends only on the volume ratio $V_{1} / V_{2}$ and the parameter $Q_{12} /\left(K_{L 2} A_{S 2}\right)$ and can be expressed as follows:

$$
\begin{aligned}
\ell(\infty)= & 0.5\left(1-\frac{Q_{12}}{K_{L 2} A_{S 2}}\left(1+\frac{V_{2}}{V_{1}}\right)\right. \\
& \left.+\sqrt{\left(\frac{Q_{12}}{K_{L 2} A_{S 2}}\left(1+\frac{V_{2}}{V_{1}}\right)+1\right)^{2}-4 \frac{Q_{12}}{K_{L 2} A_{S 2}} \frac{V_{2}}{V_{1}}}\right)
\end{aligned}
$$




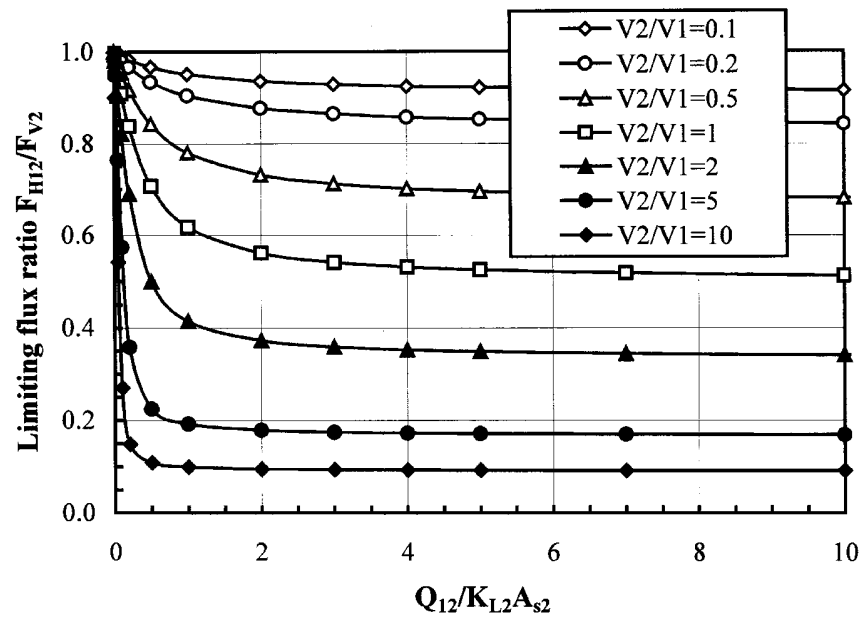

Fig. 3. Variation of the limiting flux ratio with $q=Q_{12} /\left(K_{L 2} A_{S 2}\right)$ for different values of $V_{2} / V_{1}$

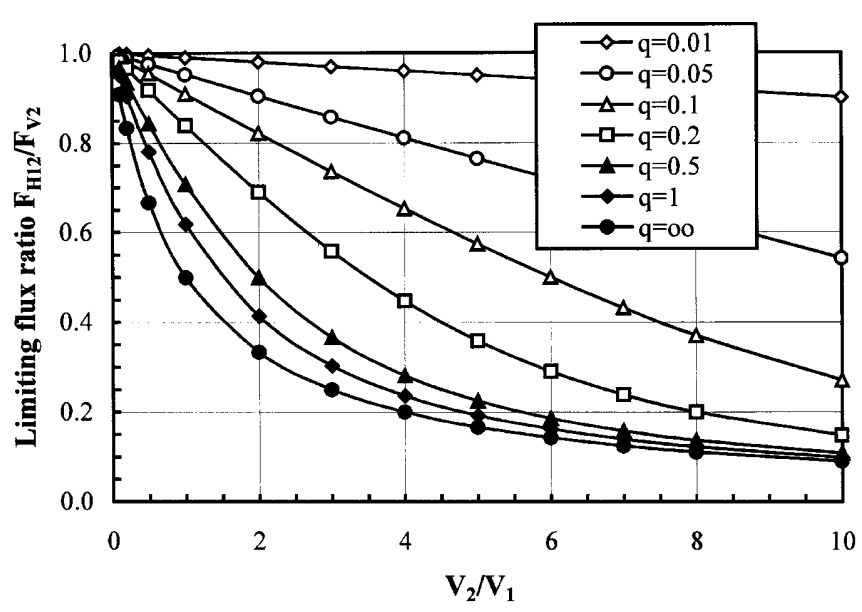

Fig. 4. Variation of the limiting flux ratio with $V_{2} / V_{1}$ for different values of $q$

The limiting flux ratio increases with increasing gas transfer coefficient and decreases with increasing exchange flux $Q_{12}$. The variation of the limiting flux ratio $\ell(\infty)$, computed from Eq. (20), with the parameter $q=Q_{12} /\left(K_{L 2} A_{S 2}\right)$ for a number of different values of the volume ratio $V_{2} / V_{1}$ is shown in Fig. 3.

In Fig. 4 the variation of the limiting flux ratio with the volume ratio $V_{2} / V_{1}$ is shown for a number of different values of the parameter $q$. It is further shown in the Appendix that when the parameter $q=Q_{12} /\left(K_{L 2} A_{S 2}\right)$ tends to infinity the limiting flux ratio depends only on the volume ratio:

$\left.\ell(\infty)\right|_{q \rightarrow \infty}=\frac{1}{1+\left(V_{2} / V_{1}\right)}=\frac{V_{1}}{V_{1}+V_{2}}$

This case represents a structure that presents no resistance to the horizontal transport (as could be the case for floating structures) and the oxygen input from reaeration is segmented in the two areas in proportion to the corresponding volumes.
Determination of $K_{L 2}$ and $Q_{12}$

The system of Eqs. (10) and (11) contains three unknowns: $D_{12}, K_{L 1}$ and $K_{L 2}$. If the barrier between areas (1) and (2) is impermeable, $D_{12}=0$ and Eqs. (10) and (11) are independent. In the case of a breakwater structure, the harbour side essentially experiences no waves and consequently no reaeration, therefore $K_{L 1} \approx 0$ and $F_{V 1} \approx 0$. Thus, the corresponding oxygenation term can be neglected compared to the oxygenation term of the seaward side, as also shown experimentally. Equations (10) and (11) can be solved for the oxygen transfer coefficient $K_{L 2}$ and the exchange flow rate $Q_{12}$ :

$$
\begin{aligned}
K_{L 2}= & -\frac{1}{A_{S 2}\left(C_{S}-C_{2}\right)} \\
& \times\left[V_{1} \frac{\mathrm{d}}{\mathrm{d} t}\left(C_{S}-C_{1}\right)+V_{2} \frac{\mathrm{d}}{\mathrm{d} t}\left(C_{S}-C_{2}\right)\right] \\
Q_{12}= & \frac{V_{1}}{\left(C_{1}-C_{2}\right)} \frac{\mathrm{d}}{\mathrm{d} t}\left(C_{S}-C_{1}\right)
\end{aligned}
$$

The transfer coefficient determined from Eq. (22) is thus higher than the transfer coefficient determined for no horizontal transport in which the term referring to area (1) is not present. The oxygen transfer coefficient $K_{L 2}$ and the exchange flow rate $Q_{12}$ can be determined from measured concentration time histories in the areas in front of and behind the breakwater structure.

\section{Laboratory experiments}

Experiments were performed in the wave flume of the LHW to study the transport of dissolved oxygen near a coastal structure of the rubble mound type with sloping fronts (Moutzouris and Daniil, 1995; Chitiroglou, 1996; Karakitsou, 1996). The dimensions of the flume were $27.40 \mathrm{~m}$ (length) $\times 0.60 \mathrm{~m}$ (width) $\times 1.53 \mathrm{~m}$ (depth). A model breakwater structure was placed in the flume with seaward and harbour side slopes of 1 (vertical):1.5 (horizontal). The crest was located at a distance of $15 \mathrm{~m}$ from the wave generator. Monochromatic waves were created by a piston type wave generator and broke over the breakwater.

Prior to each experiment, the water was deoxygenated almost completely using chemicals or nitrogen stripping. After wave initiation, dissolved oxygen concentration in the flume was measured at four locations along the flume in front of and behind the structure. Further details on the experimental setup and procedure have been presented by Daniil et al. (1998).

Wave heights ranged from 5.6 to $28.0 \mathrm{~cm}$ and wave periods from 0.75 to $1.75 \mathrm{~s}$. Wave characteristics were measured with three wave gauges and the data analyzed with Notebook software from LABTECH. The water depth ranged from 0.56 to $0.83 \mathrm{~m}$. For the first five series of experiments the breakwater structure was permeable. The breakwater was constructed using 
Table 1. Experimental conditions

\begin{tabular}{|c|c|c|c|c|c|c|}
\hline $\begin{array}{l}\text { Experiment } \\
\text { number }\end{array}$ & $\begin{array}{l}\text { Wave } \\
\text { height } \\
H(\mathrm{~cm})\end{array}$ & $\begin{array}{l}\text { Wave } \\
\text { period } \\
T(\mathrm{~s})\end{array}$ & $\begin{array}{l}\text { Water } \\
\text { depth } \\
d(\mathrm{~m})\end{array}$ & $\begin{array}{l}\text { Wave } \\
\text { length } \\
L(\mathrm{~m})\end{array}$ & $\begin{array}{l}\text { Water } \\
\text { temperature } \\
\theta\left({ }^{\circ} \mathrm{C}\right)\end{array}$ & $\begin{array}{l}\text { Atmospheric } \\
\text { pressure } \\
P(\mathrm{mmHg})\end{array}$ \\
\hline \multicolumn{7}{|c|}{ Permeable breakwater structure } \\
\hline I1B & 7.10 & 0.75 & 0.60 & 0.88 & 15.3 & 749 \\
\hline $\mathrm{I} 2 \mathrm{~A}$ & 9.90 & 1.60 & 0.60 & 3.27 & 14.9 & 747 \\
\hline $\mathrm{I} 2 \mathrm{~B}$ & 5.60 & 0.75 & 0.60 & 0.88 & 14.7 & 747 \\
\hline I6 & 28.00 & 1.45 & 0.83 & 3.07 & 12.7 & 757.5 \\
\hline SA1 & 11.95 & 1.75 & 0.76 & 3.98 & 14.4 & 755 \\
\hline SA2 & 17.20 & 1.75 & 0.76 & 3.98 & 14.6 & 756 \\
\hline SA3 & 7.00 & 1.75 & 0.76 & 3.98 & 12.5 & 760 \\
\hline SA4 & 6.60 & 1.04 & 0.76 & 1.68 & 12.5 & 760 \\
\hline SA5 & 11.90 & 1.04 & 0.76 & 1.68 & 12.3 & 759 \\
\hline SA6 & 18.60 & 1.04 & 0.76 & 1.68 & 12.8 & 753 \\
\hline SB1 & 18.60 & 1.04 & 0.76 & 1.68 & 14.3 & 755 \\
\hline SB2 & 11.90 & 1.04 & 0.76 & 1.68 & 14.1 & 752 \\
\hline SB3 & 11.95 & 1.75 & 0.76 & 3.98 & 14.3 & 751 \\
\hline SB4 & 17.20 & 1.75 & 0.76 & 3.98 & 13.9 & 745 \\
\hline SN1 & 11.20 & 1.23 & 0.76 & 2.29 & 16.4 & 753 \\
\hline SN2 & 16.00 & 1.23 & 0.76 & 2.29 & 16.0 & 749 \\
\hline SN3 & 20.00 & 1.23 & 0.76 & 2.29 & 15.5 & 755 \\
\hline A1 & 12.40 & 1.04 & 0.56 & 1.64 & 16.4 & 753 \\
\hline $\mathrm{A} 2$ & 7.05 & 1.04 & 0.56 & 1.64 & 16.0 & 749 \\
\hline A3 & 11.70 & 1.75 & 0.56 & 3.60 & 15.5 & 755 \\
\hline \multicolumn{7}{|c|}{ Impermeable breakwater structure } \\
\hline $\mathrm{AI} 2$ & 12.40 & 1.04 & 0.56 & 1.64 & 22.5 & 753 \\
\hline AI3 & 7.05 & 1.04 & 0.56 & 1.64 & 22.5 & 750 \\
\hline AI4 & 11.70 & 1.75 & 0.56 & 3.60 & 22.5 & 746 \\
\hline AI5 & 11.90 & 1.23 & 0.56 & 2.18 & 21.8 & 750 \\
\hline
\end{tabular}

angular stones having an average mass of $0.095 \mathrm{~kg}$, mean diameter $D_{50}=0.033 \mathrm{~m}$ and density $\rho_{s}=2650 \mathrm{~kg} /$ $\mathrm{m}^{3}$. The length of the structure was varied in experiment series SA and SB; no significant difference was observed. In the last series of experiments (series AI) a plastic impermeable barrier was placed approximately $10 \mathrm{~cm}$ below the face of the breakwater (Fig. 1).

The experimental conditions, i.e. wave characteristics, water depth, water temperature and atmospheric pressure are summarized in Table 1.

Area (1) is a zone where no wave action was observed. Significant increase in DO concentration was observed when the structure was permeable. In the experiments with an impermeable structure, no DO concentration change was observed in area (1) for the whole duration of the experiment, even for zero initial DO concentration.
Characteristic DO time histories for areas (1) and (2) from experiments $\mathrm{A} 2$ and $\mathrm{AI} 3$ having the same wave characteristics, but with permeable and impermeable structure respectively, are given in Fig. 5.

\section{Results and discussion}

The main objective of the data analysis was the determination of the oxygen transfer coefficients under breaking waves on a rubble mound coastal structure and the correlation with wave characteristics. The transfer coefficients $K_{L 2}$ were deduced from the experimental data according to the preceding analysis.

The resulting values of the transfer coefficients, $K_{L 2}$, and the exchange flow rate $Q_{12}$ as determined from Eqs. (22) and (23) are given in Table 2. The "apparent"
EXP A2

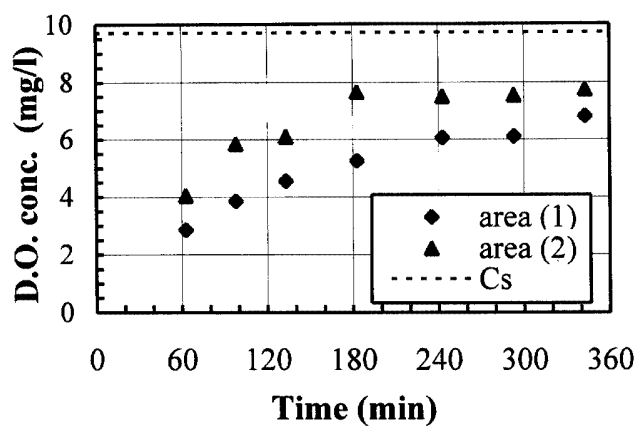

EXP AI3

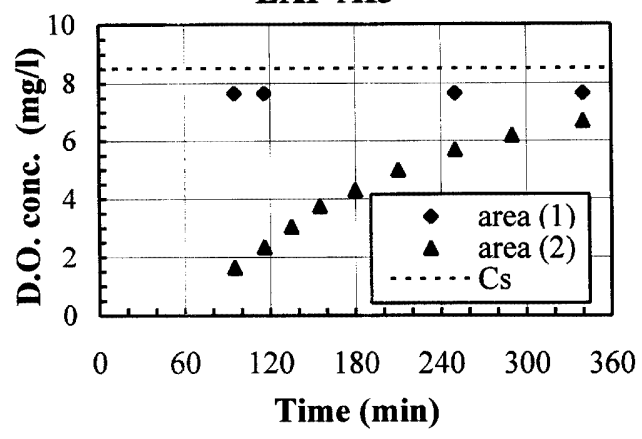

Fig. 5. Characteristic DO time histories for the permeable and impermeable breakwater structures 
Table 2. Transfer coefficients and wave parameters

\begin{tabular}{|c|c|c|c|c|c|c|}
\hline $\begin{array}{l}\text { Experiment } \\
\text { number }\end{array}$ & $\begin{array}{l}\text { Saturation } \\
\text { concentration } \\
C_{S}(\mathrm{mg} / \mathrm{l})\end{array}$ & $\begin{array}{l}\text { Schmidt } \\
\text { number } \\
S c\end{array}$ & $\begin{array}{l}\text { Transfer } \\
\text { coefficient } \\
\text { from Eq. }(26) \\
K_{L 2} S c^{0.5} \times 10^{3} \\
(\mathrm{~m} / \mathrm{s})\end{array}$ & $\begin{array}{l}\text { Apparent } \\
\text { transfer } \\
\text { coefficient } \\
\text { from Eq. }(13) \\
K_{\text {Lap }} S c^{0.5} \times 10^{3} \\
(\mathrm{~m} / \mathrm{s})\end{array}$ & $\begin{array}{l}\text { Exchange } \\
\text { flow rate } \\
Q_{12} \times 10^{3} \\
\left(\mathrm{~m}^{3} / \mathrm{sec}\right)\end{array}$ & $\begin{array}{l}\text { Wave } \\
\text { parameter }(L / d) \\
(v \omega)^{0.5} \times 10^{3} \\
(\mathrm{~m} / \mathrm{s})\end{array}$ \\
\hline \multicolumn{7}{|c|}{ Permeable breakwater structure } \\
\hline I1 B & 9.90 & 701 & 1.95 & 1.42 & 0.25 & 1.68 \\
\hline $\mathrm{I} 2 \mathrm{~A}$ & 9.90 & 716 & 1.39 & 1.09 & 0.56 & 1.57 \\
\hline $\mathrm{I} 2 \mathrm{~B}$ & 9.90 & 716 & 1.18 & 1.08 & 0.16 & 1.32 \\
\hline I6 & 10.56 & 809 & 6.00 & 4.66 & 1.40 & 3.60 \\
\hline SA1 & 10.13 & 736 & 2.32 & 1.34 & 1.69 & 1.44 \\
\hline SA2 & 10.50 & 728 & 4.10 & 2.52 & 2.80 & 2.07 \\
\hline SA3 & 10.64 & 818 & 1.28 & 0.59 & 1.94 & 0.86 \\
\hline SA4 & 10.64 & 818 & 1.28 & 0.83 & 1.82 & 1.06 \\
\hline SA5 & 10.67 & 827 & 2.47 & 1.81 & 1.73 & 1.95 \\
\hline SA6 & 10.47 & 804 & 7.88 & 4.85 & 2.44 & 3.14 \\
\hline SB1 & 10.15 & 740 & 11.4 & 4.73 & 7.94 & 3.08 \\
\hline SB2 & 10.16 & 748 & 3.34 & 1.98 & 1.47 & 1.90 \\
\hline SB3 & 10.10 & 740 & 3.62 & 1.64 & 3.43 & 1.44 \\
\hline SB4 & 10.10 & 757 & 3.16 & 2.66 & 2.81 & 2.09 \\
\hline SN1 & 10.52 & 823 & 3.13 & 1.68 & 0.66 & 1.66 \\
\hline SN2 & 10.43 & 800 & 4.27 & 2.97 & 1.80 & 2.39 \\
\hline $\mathrm{SN} 3$ & 10.51 & 814 & 7.59 & 4.96 & 2.52 & 3.04 \\
\hline A1 & 9.69 & 660 & 4.52 & 3.78 & 1.78 & 2.62 \\
\hline A2 & 9.72 & 674 & 1.76 & 1.00 & 0.38 & 1.47 \\
\hline A3 & 9.90 & 693 & 1.95 & 0.64 & 1.24 & 1.88 \\
\hline \multicolumn{7}{|c|}{ Impermeable breakwater structure } \\
\hline AI2 & 8.56 & 481 & - & 2.22 & - & 2.44 \\
\hline AI3 & 8.53 & 481 & - & 1.12 & - & 1.35 \\
\hline AI4 & 8.48 & 481 & - & 1.42 & - & 1.73 \\
\hline AI5 & 8.65 & 498 & - & 2.15 & - & 2.11 \\
\hline
\end{tabular}

transfer coefficients, $K_{\text {Lap }}$, determined using Eq. (8), i.e. neglecting the horizontal flux, are also given for comparison. For the experiments with the impermeable barrier (series AI), there is no horizontal flux through the body of the structure and therefore Eqs. (22) and (8) yield identical results.

DO concentrations computed according to Eqs. (12) and (13) as well as measured DO concentration data for the areas in front of (area 2) and behind (area 1) the permeable breakwater structure are shown in Fig. 6 for six different experiments. The initial condition is specified to match experimental data. Measured and predicted values are in good agreement, justifying the use of the two-cell model for the analysis.

In Fig. 7 the coefficients $K_{L 2}$ and $K_{\text {Lap }}$ are plotted versus the wave parameter $(L / d)(v \omega)^{0.5}$ used by Daniil and Moutzouris (1995). The $K_{L 2}$ values were found to be higher than the $K_{\text {Lap }}$ values, as expected from the preceding discussion of Eq. (22). Equation (4) for the smooth sloping beach and Eq. (5) for the breakwater are also shown. Note that coefficients $A^{\prime}$ and $B^{\prime}$ in Eq. (5) were determined based on the preliminary analysis of the first series of experiments (Daniil and Moutzouris, 1995) in which the effect of horizontal transport was not taken into account. The close agreement between Eq. (4) and the $K_{L 2}$ values implies that the actual oxygenation due to breaking waves on a sloping surface does not depend on the type of surface, i.e. it is essentially the same for a smooth sloping beach and a rubble mound coastal structure. In this context it is useful to note some similarities and differences observed by other researchers relating to the two kinds of structure and the type of wave breaking.

Hughes and Fowler (1995) in their study of wave induced kinematics at sloping structures mentioned that the magnitude and spatial variation of root mean squared water velocities near a structure are primarily a function of the incident wave conditions, water depth, location relative to the structure toe and the structure slope and permeability. They determined separate empirical equations for estimating reflection coefficients for the cases of smooth impermeable structures and rubble mound structures, whereas the reflection phase angle was represented adequately by a single equation for both structure types. Sutherland and O'Donoghue (1998) conducted experiments with rubble mound breakwaters that confirm the findings of Hughes and Fowler (1995), that the phase shift on reflection is the same for rubble mound breakwaters as it is for smooth structures with the same seaward slope and toe depth.

Finally, regarding the differences between spilling and plunging breaking waves Papanicolaou and Raichlen (1988) mention that the initial characteristics of the breaking wave just at the beginning of formation of the bubble plume on the front face of the wave must be similar for shallow water and deep water waves, both 
EXP I1B

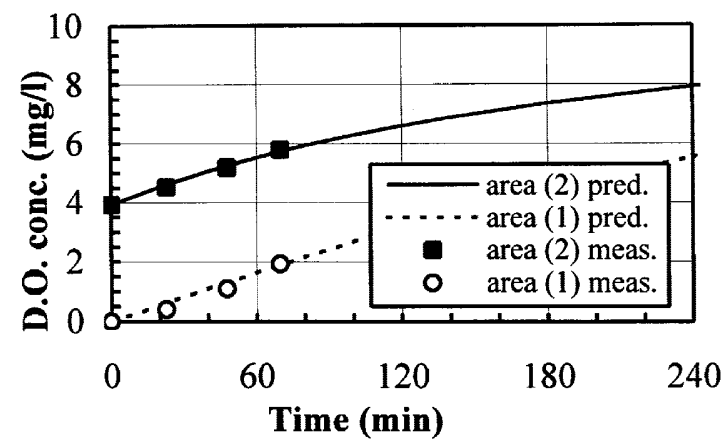

EXP I2A

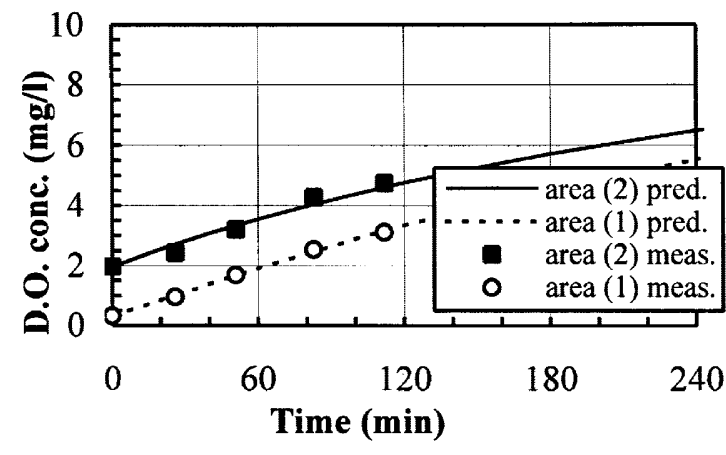

EXP SA2

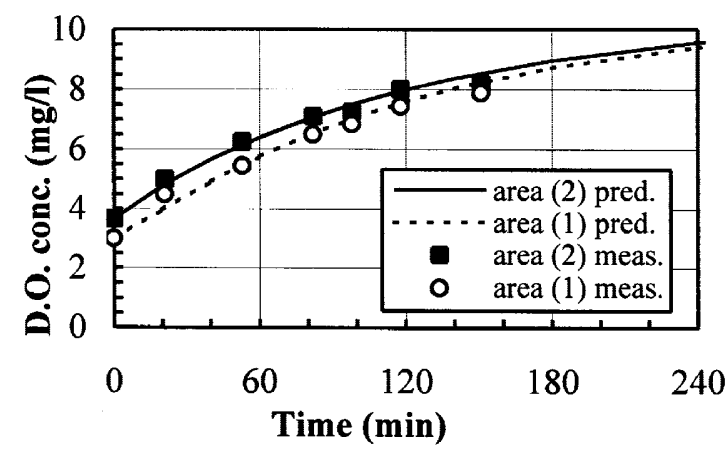

EXP SA4

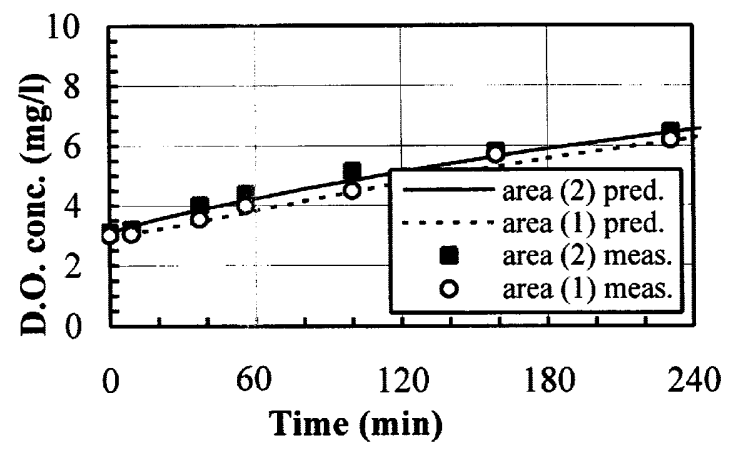

EXP SA6

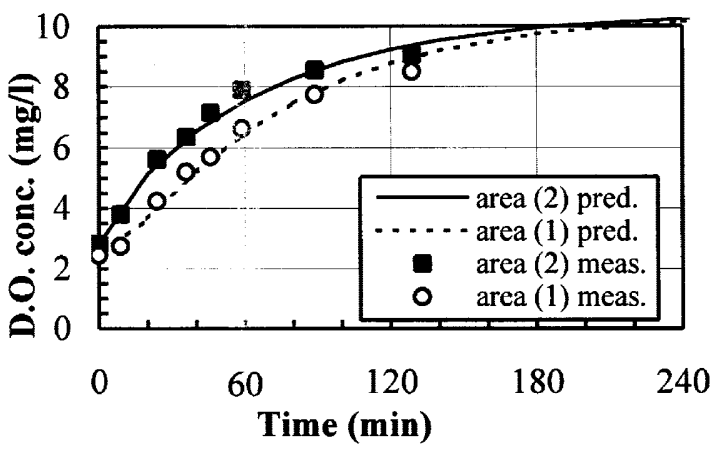

EXP SN2

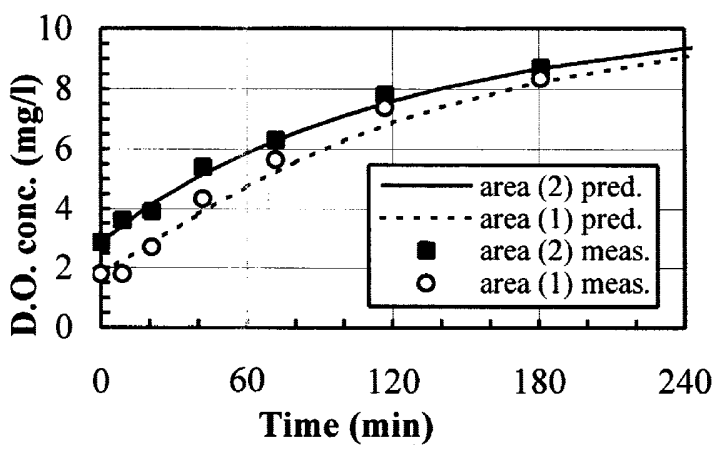

Fig. 6. Measured and predicted DO time histories for the areas in front of and behind a permeable breakwater structure

for their plunging and spilling breaker counterparts. Also the higher frequency noise generated by the breaking is similar both for plunging and spilling breaking waves.

In Fig. 8 transfer coefficients from experiments with permeable and impermeable rubble mound structures, after accounting for horizontal transport, are plotted against the parameter $(L / d)(v \omega)^{1 / 2}$. Data from experiments with the impermeable structure (series AI) follow the same trend.

The coefficients in Eq. (5) were reevaluated using the data from 20 experiments with permeable structures to yield:

$K_{L} S c^{1 / 2}=3.03(L / d)(v \omega)^{1 / 2}-2.36 \times 10^{-3}$
The coefficients are practically the same as those in Eq. (4), which was developed based on eight experiments only. The correlation coefficient is again high $\left(r_{c}=0.847\right)$.

The parameter flow rate $Q_{12}$, as already mentioned, does not depend only on wave dynamics, but also on the characteristics of the structure. The values of $Q_{12}$ also contain uncertainties resulting from its determination from Eq. (23) when DO concentration differences in areas (1) and (2) are low. In Fig. 9 correlation of the exchange flow rate $Q_{12}$ with the wave parameter $(L / d)(v \omega)^{0.5}$ is attempted. A linear regression fit yields the following equation:

$Q_{12}=0.94(L / d)(v \omega)^{1 / 2}+5.4 \times 10^{-5}$ 

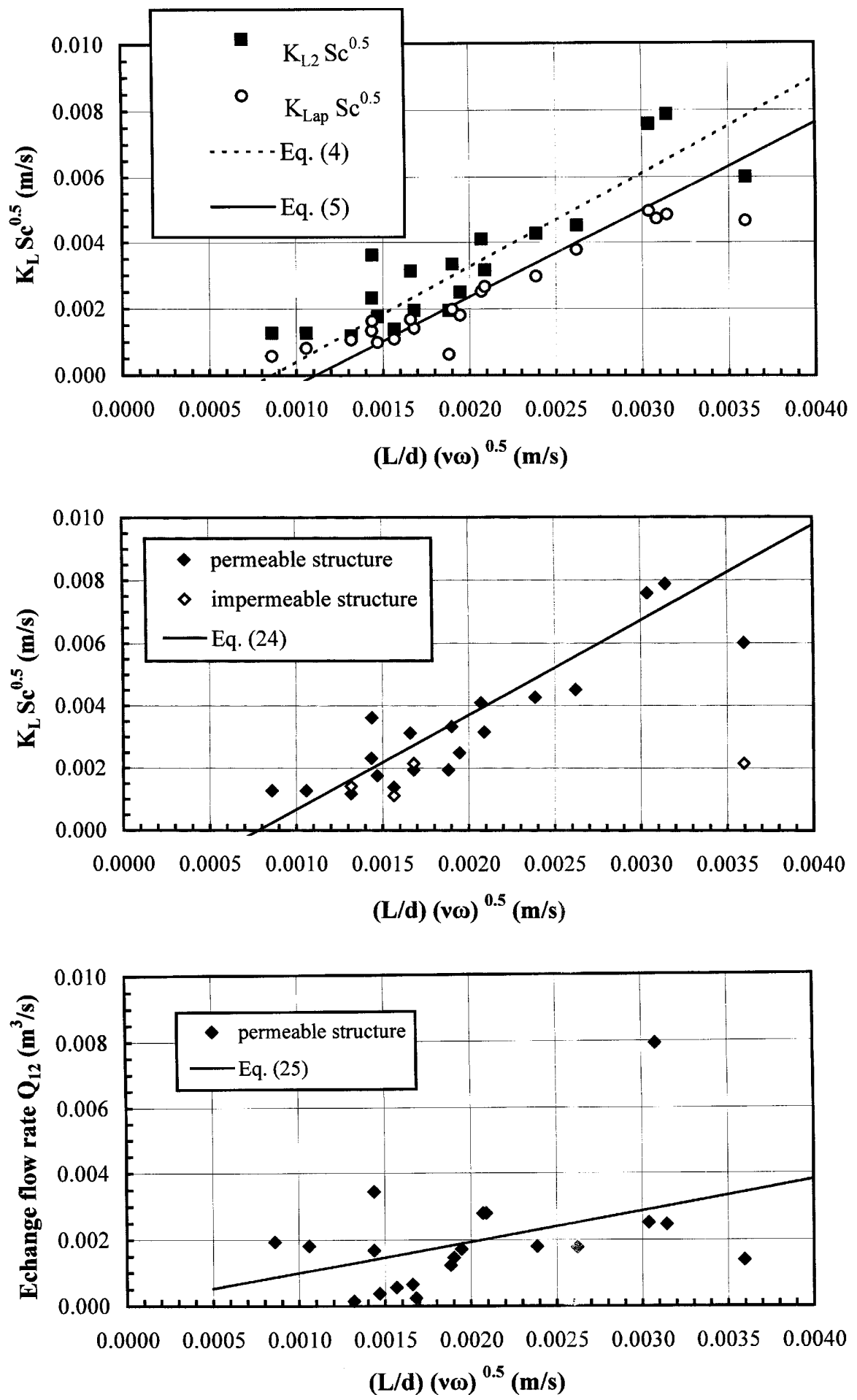

Fig. 7. Comparison of transfer coefficients and apparent transfer coefficients for permeable rubble mound structures with Eqs. (4) and (5)
Fig. 8. Correlation of the transfer coefficients of permeable and impermeable rubble mound structures with the wave parameter $(L / d)(v \omega)^{0.5}$
Fig. 9. Correlation of the exchange flow rate $Q_{12}$ with the wave parameter $(L / d)(v \omega)^{0.5}$ with a relatively low correlation coefficient $\left(r_{c}=0.42\right)$ as expected, since additional parameters should be included in the final formulation. Parametrization of $Q_{12}$ with wave and structure characteristics should be further investigated analytically and experimentally.

\section{Critical examination of assumptions and results}

The developed two-cell model presents an improved tool compared to the simple equation, assuming horizontal transport to be negligible, usually used for determination of the oxygen transfer coefficient. Even so, it is a simplified approach, that treats the rubble mound structure as a barrier between the wave influenced area and the harbour area. Special cases, where the DO gradient between the areas in front of and behind the structure is not the driving force for the horizontal transport, e.g. when DO content in the structure is substantially lower or higher than the two areas considered, cannot be treated correctly with the two- 
cell model. More complicated cases would require a model with more cells or even a 3-D model. The analytical results provide useful insight on the process and can be used in a qualitative way or as first-guess values for the more complicated cases where the solutions will have to be obtained numerically.

\section{Conclusions}

The beneficial role of rubble mound structures on seawater oxygenation has been demonstrated based on experimental data and the analytical solution of a twocell model. Experimental data were collected in the vicinity of permeable and impermeable rubble mound structures. Breaking waves on a sloping surface result in high oxygenation rates. Additionally, for permeable structures significant oxygenation of the wave-protected area is observed due to horizontal dissolved oxygen transport through the body of the structure. Experiments with impermeable structures have shown that oxygen transfer in the wave-protected area (harbour side) may be neglected.

A two-cell model describing the dissolved oxygen (DO) transport in both sides of a permeable coastal structure was developed. Oxygen transfer across the airsea interface in the wave-influenced area was considered a source term. The behaviour of the analytical solution was illustrated for three characteristic cases of initial DO conditions. Although, in each case the oxygen transfer rate through the air-sea interface depends only on the wave characteristics, the observed DO concentration change in the wave-influenced area is also controlled by the DO concentration difference between the two sides of the structure. The more commonly encountered case is that the DO concentration in the wave-influenced area is higher and the oxygen transfer is only partly translated to an increase of DO concentration of this area, while the rest is transported through the structure.

The solutions depend on the initial conditions, the oxygen transfer coefficient and the exchange flow rate through the structure. Experiments with impermeable structure show that when no waves are present, airwater-oxygen transfer in the harbour area is negligible. It is also shown that the ratio of the horizontal flux to the vertical flux into the seaward side tends to a constant value, independent of the initial conditions.

The model can also be used for determining the oxygen transfer coefficient in the area in front of a permeable breakwater structure and the exchange flow rate through the body of the structure from experimentally measured DO time histories, as in the case of the experiments presented herein.

The correlation of the exchange flow rate through the body of the structure with the vorticity wave parameter is relatively poor. The reason for this is two-fold: uncertainties resulting from the determination of the exchange flow rate from the DO concentration data and the fact that the characteristics of the structure were not included. Parametrization of the exchange flow rate has to be further investigated.
Acknowledgements. The authors thank the reviewers for their constructive critique and valuable comments towards a more concise presentation of the developed model.

Topical Editor N. Pinardi thanks H. Chanson and G. Horsch for their help in evaluating this paper.

\section{References}

Asher, W. E., and R. Wanninkhof, The effect of bubble - mediated gas transfer on purposeful dual-gaseous tracer experiments, J. Geophys. Res., 103(C5), 10 555-10 560, 1998.

Asher, W. E., L. M. Karle, B. J. Higgins, P. J. Farley, E. C. Monahan, and I. S. Leifer, The influence of bubble plumes on air-sea water gas transfer velocities, J. Geophys. Res., 101(C5), 12 027-12 041, 1996.

Bennett, J. P., and R. E. Rathbun, Reaeration in open-channel flow, U.S. Geol. Surv., Prof. pap., 737, 1972.

Chanson, H., and P. D. Cummings, Prediction of bubble entrainment due to storm waves, Proc. of $X X V$ Congress of IAHR, Tokyo, Japan, 80-87, 1993.

Chanson, H., and P. D. Cummings, Effects of Plunging Breakers on the gas contents in the oceans, Mar. Techn. Soc. J., 28(3), 22-32 1994.

Chanson, H., and J. F. Lee, Plunging jet characteristics of plunging breakers, Coast. Eng., 31(1-4), 125-141, 1997.

Chitiroglou, S., Experimental study of seawater oxygenation under the effect of waves in front of a sloping breakwater structure, Diploma Thesis (in Greek), Faculty of Civil Eng., Lab. of Harbour Works, NTUA, 1996.

Danckwerts, P. V., Significance of liquid-film coefficients in gas adsorption, Ind. Eng. Chem., 46(6), 1460-1467, 1951.

Daniil, E. I., and C. I. Moutzouris, Oxygenation experiments in the wave breaking zone, Hydraulic Engineering 93, In: Eds., H. W. Shen, S. T. Su, and F. Wen, ASCE, 2008-2013, 1993.

Daniil, E. I., and C. I. Moutzouris, A vorticity - based model for gas transfer under breaking waves, Ann. Geophysicae, EGS, 13, 1039-1046, 1995.

Daniil, E. I., V. K. Tsoukala, and C. I. Moutzouris, Harbour basin seawater oxygenation through rubble mound breakwater structures, J. Mar. Environ. Eng., 4(4), 277-300, 1998.

Horsch, G. M., Steady, diffusive - reactive transport in shallow triangular domain, ASCE, J. Eng. Mech., 124(10), 1135-1141, 1998.

Hosoi, Y., and H. Murakami, Effect of waves on dissolved oxygen and organic matter, 20th Coastal Eng. Conference, Proc. CERC, ASCE, Taipei, 2498-2512, 1986.

Hosoi, Y., and H. Murakami, Model of reaeration at permeable breakwaters, in Air water gas transfer, Eds. B. Jähne, and E. C. Monahan, 473-483 1995. AEON Verlag \& Studio, Hanau, Germany.

Hosoi, Y., H. Murakami, and H. Mitsui, Reaeration due to wave breaking at coastal structures, Coast. Eng. Japan, 33(1), 89-100, 1990.

Hughes, S. A., and J. E. Fowler, Estimating wave-induced kinematics at sloping structures, ASCE, J. Waterway, Port, Coast. Ocean Eng., 121(4), 209-215, 1995.

Karakitsou, A., Experimental study of seawater oxygenation through a breakwater structure, Diploma Thesis (in Greek), Faculty of Civil Eng., Lab. of Harbour Works, NTUA, 1996.

Lin, P., and P. L.-F. Liu, Turbulence transport, vorticity dynamics, and solute mixing under plunging breaking waves in surf zone, J. Geophys. Res., 103(C8), 15 677-15 694, 1998.

Liss, P. S., Gas transfer: experiments and geochemical implications, in Air-sea exchange of gases and particles, Eds. P. S. Liss and W. G. N. Slinn, 241-298, 1983. D. Reidel, Norwell, Mass.

Moutzouris, C. I., and E. I. Daniil, Oxygenation on a sloping beach under breaking waves, Mitteil. Franzius Ins. Wasserb. Künsteningenieurwesen Universität Hannover, 75, 88-99, 1994. 
Moutzouris, C. I., and E. I. Daniil, Water oxygenation in the vicinity of coastal structures due to wave breaking, in Coastal engineering 1994, Ed. B. L. Edge, Proc. 24th Int. Conf. held in Kobe, Japan, ASCE, NY. 3167-3177, 1995.

Papanicolaou, P., and F. Raichlen, Wave and bubble characteristics in the surf zones, in Sea surface sound. Ed. B. R. Kerman, 97109, 1988. Kluwer, Hingham, Mass.

Patankar, S. V., Numerical heat transfer and fluid flow, Mc GrawHill, 1980.

Stefan, H. G., G. M. Horsch, and J. W. Barko, A model for the estimation of convective exchange in the littoral region of a shallow lake during cooling, Hydrobiologia, 174, 225-234, 1989.

Sutherland, J., and T.O'. Donogue, Wave phase shift at coastal structures, J. Waterway, Port Coast. Ocean Eng., 124(2), 90-98, 1998.

Tsoukala, V. K., and C. I. Moutzouris, Oxygenation of sea water under breaking waves (In greek) in Proc. 4th Conf. on Environm. Science and Technology, Molyvos, Lesvos, Greece, In: Ed. T. Lekkas, 178-187, 1995.

Tuma, J. J., Engineering mathematics handbook, 3rd Edn, McGraw-Hill, Inc., USA 1987.

\section{Appendix I. Analytical solution}

Equations (10) and (11) are first order differential equations and their solution has an exponential form as indicated by Eqs. (12) and (13). The following transformations are used for a more concise presentation of the solution:

$\Phi_{i}=C_{S}-C_{i}$

$\Phi_{i}$ represents the DO concentration deficit and $\Phi_{i 0}$ indicates the initial value.

$K_{i}=\frac{K_{L i} A_{s i}}{V_{i}}$

The constants $A_{1}, B_{1}, A_{2}, B_{2}, \gamma$, and $\delta$ are expressed as functions of the characteristics of the two areas, the transfer coefficients, the exchange flow rate, and the initial DO concentration conditions at time $t=0$ as follows:

$A_{1}$

$$
=\frac{Q_{12}\left(\Phi_{10}-\Phi_{20}\right) V_{2}-0.5\left[Q_{12}\left(V_{1}+V_{2}\right)-V_{1} V_{2}\left(R-K_{2}+K_{1}\right)\right] \Phi_{10}}{V_{1} V_{2} R}
$$

$B_{1}$

$$
=\frac{-Q_{12}\left(\Phi_{10}-\Phi_{20}\right) V_{2}+0.5\left[Q_{12}\left(V_{1}+V_{2}\right)+V_{1} V_{2}\left(R+K_{2}-K_{1}\right)\right] \Phi_{10}}{V_{1} V_{2} R}
$$

$R=\left[\left(Q_{12}\left(\frac{1}{V_{1}}-\frac{1}{V_{2}}\right)+\left(K_{1}-K_{2}\right)\right)^{2}+4 \frac{Q_{12}^{2}}{V_{1} V_{2}}\right]^{1 / 2}$

$\gamma=\frac{1}{2}\left(Q_{12}\left(\frac{1}{V_{1}}+\frac{1}{V_{2}}\right)+K_{1}+K_{2}+R\right)$

$\delta=\frac{1}{2}\left(Q_{12}\left(\frac{1}{V_{1}}+\frac{1}{V_{2}}\right)+K_{1}+K_{2}-R\right)$

$A_{2}, B_{2}$ can be obtained from $A_{1}, B_{1}$ by transposing the subscripts 1,2 :

$A_{2}$

$$
=\frac{Q_{12}\left(\Phi_{20}-\Phi_{10}\right) V_{1}-0.5\left[Q_{12}\left(V_{1}+V_{2}\right)-V_{1} V_{2}\left(R-K_{1}+K_{2}\right)\right] \Phi_{20}}{V_{1} V_{2} R}
$$

$$
=\frac{-Q_{12}\left(\Phi_{20}-\Phi_{10}\right) V_{1}+0.5\left[Q_{12}\left(V_{1}+V_{2}\right)+V_{1} V_{2}\left(R+K_{1}-K_{2}\right)\right] \Phi_{20}}{V_{1} V_{2} R}
$$

For the initial time $t=0$, the following relations hold:

$\Phi_{10}=A_{1}+B_{1}$

$\Phi_{20}=A_{2}+B_{2}$

As time tends to infinity, the ratio of the oxygen deficits tends to the ratio of the coefficients $B_{1} / B_{2}$ :

$\lim _{t \rightarrow \infty} \frac{\Phi_{1}}{\Phi_{2}}=\lim _{t \rightarrow \infty} \frac{A_{1} \mathrm{e}^{-(\gamma-\delta) t}+B_{1}}{A_{2} \mathrm{e}^{-(\gamma-\delta) t}+B_{2}}=\frac{B_{1}}{B_{2}}$

since $\gamma-\delta=R>0$ and $\mathrm{e}^{-\infty}=0$.

It is shown that $B_{1} / B_{2}$ and hence the limiting flux ratio is independent of the initial conditions $\left(\Phi_{10}, \Phi_{20}\right)$.

$\frac{B_{1}}{B_{2}}=\frac{\Phi_{10}\left(Q_{12}\left(V_{1}-V_{2}\right)+\left(K_{2}-K_{1}+R\right) V_{1} V_{2}\right)+\Phi_{20} 2 Q_{12} V_{2}}{\Phi_{10} 2 Q_{12} V_{1}+\Phi_{20}\left(Q_{12}\left(V_{2}-V_{1}\right)+\left(K_{1}-K_{2}+R\right) V_{1} V_{2}\right)}$

It is easily proven that the coefficients of $\Phi_{10}$ and $\Phi_{20}$ in the numerator and the denominator are proportional and therefore the ratio $B_{1} / B_{2}$ is equal to this constant of proportionality and independent of $\Phi_{10}, \Phi_{20}$.

$\frac{B_{1}}{B_{2}}=\frac{1}{2}\left[1-\frac{V_{2}}{V_{1}}+\frac{V_{2}}{Q_{12}}\left(K_{2}-K_{1}+R\right)\right]$

The same result can also be obtained either by l'Hospital's rule or by taking partial derivatives with respect to $\Phi_{10}, \Phi_{20}$, but the procedure is more tedious. According to this the limiting flux ratio can be expressed as:

$$
\begin{aligned}
\ell(\infty) & =\frac{Q_{12}}{K_{2} V_{2}}\left(\frac{B_{1}}{B_{2}}-1\right) \\
& =\frac{1}{2}\left(\frac{R-K_{1}}{K_{2}}+1-\frac{Q_{12}}{K_{2} V_{1}}\left(1+\frac{V_{1}}{V_{2}}\right)\right) \\
\text { For } K_{1} & =0 \quad \frac{R}{K_{2}}=\sqrt{\left(\frac{Q_{12}}{K_{2} V_{1}}\left(1+\frac{V_{1}}{V_{2}}\right)+1\right)^{2}-\frac{4 Q_{12}}{K_{2} V_{1}}}
\end{aligned}
$$

Substituting Eq. (40) into Eq. (39), Eq. (20) is derived. Setting

$$
\begin{aligned}
& q=\frac{Q_{12}}{K_{L 2} A_{S 2}} \\
& v=\frac{V_{2}}{V_{1}}
\end{aligned}
$$

Eq. (20) is written:

$\ell(\infty)=0.5\left[1-q(1+v)+\sqrt{(q(1+v)+1)^{2}-4 q v}\right]$

Further the dependence of the limiting flux ratio on the volume ratio, $v$, is examined for the case when the parameter $q$ tends to infinity. For $q \rightarrow \infty, 1 / q \rightarrow 0$ and the corresponding $1 / q$ terms are omitted. Therefore,

$\lim _{q \rightarrow \infty} \frac{\partial}{\partial q} \ell(\infty)=0.5 \lim _{q \rightarrow \infty}\left[-(1+v)+\frac{2\left(1+v+\frac{1}{q}\right)(1+v)-\frac{4 v}{q}}{\sqrt{\left(1+v+\frac{1}{q}\right)^{2}-\frac{4 v}{q^{2}}}}\right]=0$

and the limiting flux ratio depends only on $v$.

Setting

$X=q(1+v)$ 


$$
\lim _{q \rightarrow \infty} \ell(\infty)=0.5\left[1-X+X \sqrt{1+\frac{2}{X}+\frac{1}{X^{2}}-\frac{4 q v}{X}}\right]
$$

For $q \rightarrow \infty, 1 / X \rightarrow 0$ and the square root term can be approximated by series expansion as $\sqrt{1+x} \approx 1+\frac{x}{2}$ with error $\varepsilon_{\mathrm{T}}<0.1 \%$ for $-0.08 \leq \mathrm{x} \leq 0.10$ and $\varepsilon_{\mathrm{T}}<1 \%$ for $-0.24 \leq \mathrm{x} \leq 0.32$ (Tuma, 1987).

$$
\begin{aligned}
\lim _{q \rightarrow \infty} \ell(\infty) & \cong 0.5\left[1-X+X\left(1+\frac{1}{X}+\frac{1}{2 X^{2}}-\frac{2 q v}{X}\right)\right] \\
& =0.5\left(2+\frac{1}{2 X}-\frac{2 q v}{X}\right)=\frac{1}{1+v}
\end{aligned}
$$

For a given volume ratio this value is the lower limit of the limiting flux ratio as can also be seen in Fig. 4. 